\title{
Assessment of Regional Site-Specific Sorghum Ergot Severity Potential Using Radar-Rainfall Measurement
}

\author{
F. Workneh, Texas Agricultural Experiment Station, Bushland 79012; B. Narasimhan and R. Srinivasan, Depart- \\ ment of Forest Science, Spatial Statistics Laboratory, Texas A \& M University, College Station 77843; and \\ C. M. Rush, Texas Agricultural Experiment Station, Bushland 79012
}

The United States produces approximately $25 \%$ (14) of the world grain sorghum on an estimated 3 to 3.6 million hectares annually. A large proportion of grain sorghum produced in the country is used for livestock feeding, and most of the production is concentrated in the Great Plains and south-central states. Kansas is the leading state in production, followed by Texas, and in 2004, these two states accounted for $72.2 \%$ (42.7 and $29.5 \%$, respectively) of the total grain sorghum planted acreage in the country (1). In addition to grain sorghum production, about 95\% of the United States' hybrid sorghum seed supply is produced in the Texas Panhandle (approximately 40,000 ha), primarily because of the absence of major pest problems (partly attributed to the desertlike climate), which provided ideal conditions for seed production. However, this changed in 1997 with the introduction of the fungus Claviceps africana Freder., Mantle, \& De Milliano, the causal agent of sorghum ergot (8).

Since its first detection in 1997, sorghum ergot has been consistently present in the Texas Panhandle and periodically has caused widespread damage (Fig. 1). During the first year of its introduction, nearly $45 \%$ of the seed production fields in the region were affected. Ergot prevalence in the region declined during the subsequent 3 years, and the threat of the disease appeared to have diminished. However, cross-spectral analysis of historic temperature and rainfall data for the Panhandle predicted that occurrences of ergotfavorable conditions in the region are periodic rather than a regular year-to-year phenomenon (20). As predicted, in 2002, sorghum ergot affected $87 \%$ of the seed production fields in the region, some so severely that harvesting was difficult because of the sticky honeydew. There was

Corresponding author: F. Workneh

E-mail: f-workneh@tamu.edu

Accepted for publication 19 January 2006

DOI: 10.1094/PD-90-0704

(C) 2006 The American Phytopathological Society another widespread ergot epidemic in 2004 that affected over $90 \%$ of the fields in the Panhandle.

In collaboration with various seed companies in the region, we have been monitoring the prevalence of sorghum ergot in the Texas Panhandle every year since 1997. To determine the magnitude of the impact of rain on the epidemiology of sorghum ergot in the region, we collected rainfall data from three North Plain Evapotranspiration (NPET) network weather stations representing the southern (Earth), central (Bushland), and the northern (Etter) Panhandle. Total rainfall data for the months of August and September (most of the flowering occurs during these months) were collected for the past 8 years (1997 to 2004). The scatter diagram of the relationship between rainfall amount and the percentage of fields with ergot showed a moderately high correlation $(r=0.72, P<$ 0.0001 ) (Fig. 2; the scatter plot and the confidence ellipse were generated using SAS software, SAS Institute Inc., Cary, NC). Rainfall frequency also correlated significantly with prevalence of the disease, but to a lesser degree than rainfall amount $(r=0.54, P=0.0059$, data not shown).

C. africana generally requires cool weather and humid conditions for opti-

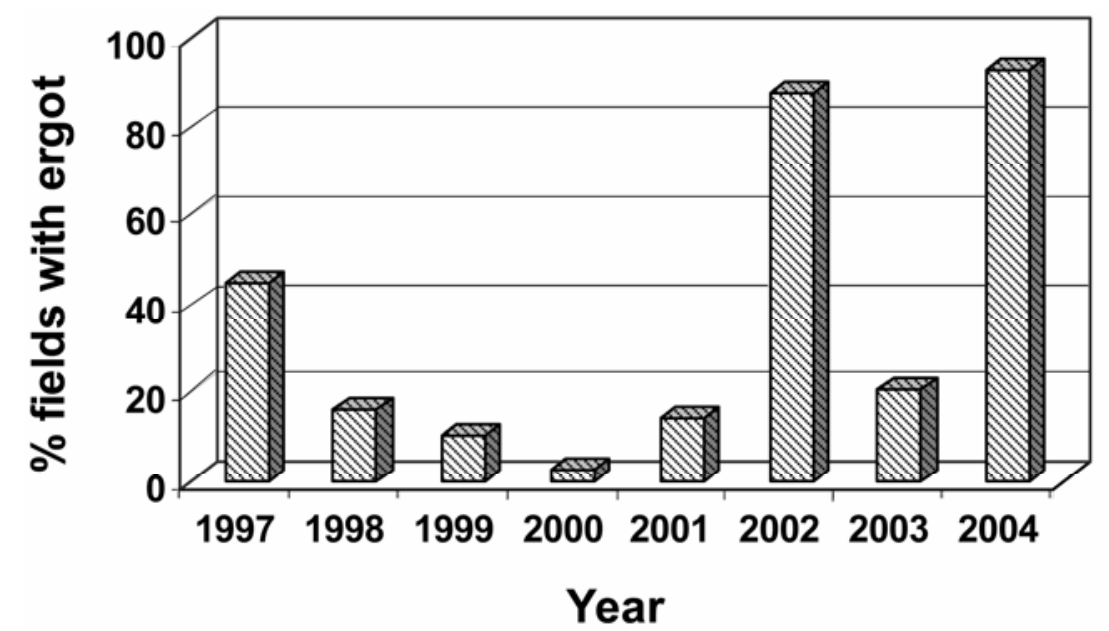

Fig. 1. Percent sorghum hybrid-seed production fields in the Texas Panhandle affected by sorghum ergot from 1997 to 2004 (an average of approximately 200 fields per year). mum infection (5). Rainfall reportedly is not required for infection as long as relative humidity is high (2). However, the Texas Panhandle is characterized by a desert-like climate with hot, dry weather during the summer. Maximum temperatures ranging between 35 and $40^{\circ} \mathrm{C}$, accompanied by low relative humidity, are not uncommon during sorghum flowering season. Prolonged occurrences of high humidity during the summer are usually associated with rain showers. In this region, rain also plays a significant role in suppression of maximum temperature such that it remains within ergot favorable range (20). A sudden drop of several degrees in temperature is not an uncommon event during an afternoon rain shower. Furthermore, rainy and damp weather that favors ergot development is suboptimal for pollination and can lead to a reduction in pollination efficiency, exposing the ovaries to infection. Rainfall also may be instrumental in washing spores of the pathogen from the air and may also play a major role in spore release from the honeydew matrix and subsequent dispersal in the form of wind-driven aerosol. Therefore, it stands to reason that rainfall has to be a major component of any regional ergot risk-assessment system in the Texas Panhandle. 
Rainfall, as important as it may be in influencing the regional ecosystem, is one of the most spatially variable weather factors $(3,7,12)$. Rainfall events are often sparse and irregular and can vary within a small area both in incidence and intensity. Rain gauges provide point measurements, and existing ground weather stations are too far apart to provide accurate representation of localized rainfall events. Data on relationships between rain gauge density and rainfall spatial variability are scanty, but the few studies that exist indicate that a rain gauge spacing of less than $5 \mathrm{~km}$ would be required to explain more than $90 \%$ of the variability $(3,7)$. This is far below the current distances between existing weather stations, which often exceed $50 \mathrm{~km}$ (13), and too wide to account for local rainfall variability. The lack of adequate data on spatial variability of precipitation has been a major hindrance in site-specific implementation of decision support systems for rain-driven plant disease epidemics. Radar-estimated rainfall may provide a potential solution to the lack of site-specificity in rain gaugebased rainfall data.

Radar-based precipitation estimates have greater spatial resolution and coverage than gauge-based point-precipitation measurements (18). NEXRAD (Next Generation Weather Radar), commonly known as Doppler radar, which has been in operation in the United States since the early 1990s, generates a large number of diverse meteorological and hydrological products, including real-time hourly rainfall and wind velocity $(4,11)$. NEXRAD provides a $4 \times 4 \mathrm{~km}$ resolution for rainfall measurement out to a radius of $230 \mathrm{~km}$ from radar location $(4,17)$. More detailed information on the radar operation system in the United States and its potential use for plant disease risk forecast has been described elsewhere $(4,19)$. The primary objective of this investigation was to assess the feasibility of using radar-estimated rainfall in development of a regional site-specific sorghum ergot forecast system for the Texas Panhandle.

\section{MATERIALS AND METHODS}

Radar rainfall data processing and acquisition. Radar rainfall data are processed in several stages. In stage I, the raw radar reflectivity is converted into rainfall depth using a reflectivity-precipitation rate (Z-R) relationship (4). The stage I data are further corrected (bias adjusted) at the National Weather Service River Forecast Centers using ground truth rain gauge data (stage II). The stage III processing involves making a mosaic of the precipitation estimates from multiple radars to further reduce any errors by using better estimates from overlapping radars. The stage III product is generally used for estimation of hourly rainfall amount. The processed data are archived in XMRG file format on polar stereographic projection called hydrologic rainfall analysis project (HRAP) with spatial resolution of $4 \times 4 \mathrm{~km}(4,17)$. The HRAP grid is a coordinate system used for defining individual grid cells of the radar data. For this project, the stage III radar rainfall data for the Texas Panhandle were obtained from the Arkansas-Red Basin (Tulsa, OK) and the West Gulf (Fort Worth, TX) River Forecast Centers via $f t p$ and decoded into an ASCII format in ArcInfo.

Ergot severity map development. After acquisition, the radar rainfall data in each grid were incorporated into weatherbased sorghum ergot severity models (21) in an ArcInfo-GIS system using the arc macro language (AML). Two ergot severity models, based on cumulative departures of temperature and relative humidity from maximum and minimum thresholds, respectively, were used as inputs. The two models were similar except that the departures were accumulated after spore deposition over an 18-h period for one (18-h model), and over a 24-h period for the other (24-h model). Whenever there was at least $2.5 \mathrm{~mm}$ of rainfall in the HRAP grid, a relative humidity value of $90 \%$ was entered in the models. Otherwise, both temperature and relative humidity values for the models in each grid cell were interpolated using the spline interpolation method from the nearest station of the 15 NPET weather stations scattered throughout the Panhandle. An ergot severity map for the Panhandle for each model then was created from the $4 \times 4 \mathrm{~km}$ grid points using the inverse distance weighting (IDW) interpolation technique for two dates, one representing widespread rainfall events (29 August 2002) and the other localized events (7 September 2003). Both the spline and IDW interpolation methods are components of the Spatial Analyst in the ArcGIS system.

\section{RESULTS AND DISCUSSION}

The 2002 sorghum ergot epidemic described above was first observed in the first week of September, 7 days after a rain storm that passed through the region during the 24-h period ending at 6:00 A.M. on 29 August (Fig. 3). The duration between the storm event and the onset of disease matched the time between infection and honeydew development, leaving little doubt that the disease was associated with the storm. The NEXRAD precipitation data, in conjunction with the sorghum ergot severity model, was able to partition the region into multiple areas varying in ergot severity. For the 2002 epidemic, the 18-h model, using NEXRAD rainfall estimates, predicted ergot severity in the Panhandle to range between 8.5 and $31.1 \%$ sorghum floret infection per panicle (Fig. 4A). The 24-h model predicted greater ergot severity in many locations (maximum of 40\%) than the 18-h model (Fig. 4B). The greater ergot severity prediction for the 24-h model suggests that some of the florets that would not develop disease within $18 \mathrm{~h}$ after infection would develop disease after an additional $6 \mathrm{~h}$.

In 2003, sorghum ergot was observed in about $20 \%$ of the fields and was localized and sporadic. There were isolated rain showers over several days in early-to-midSeptember similar to the storm during the 24-h period ending at 6: 00 A.M. on 7 September, for which the image is shown (Fig. 5A). Thus, it was difficult to pinpoint a particular rainfall event responsible for the occurrence of the disease in 2003. For 7 September, the $24-\mathrm{h}$ model predicted 0 to $7 \%$ of the florets (per panicle) to be infected depending on the location (Fig. 5B). The 18-h model predicted slightly less ergot severity than the 24-h model (not shown). However, both models predicted zero ergot severity for areas of the Panhandle where there was no rainfall on that day.

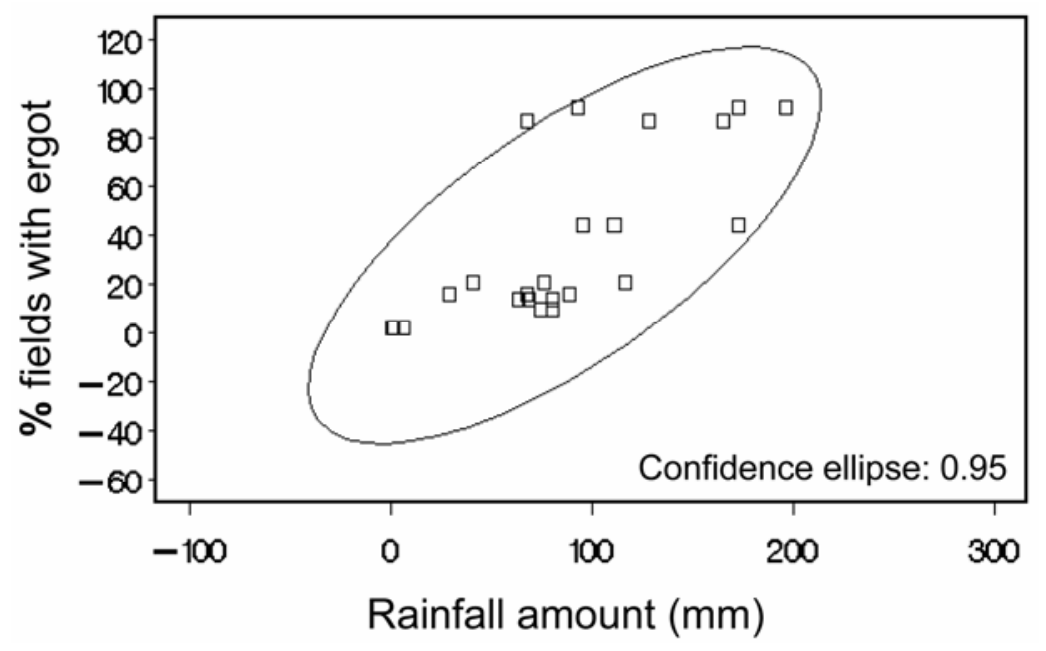

Fig. 2. Relationships between sorghum ergot prevalence (\% fields with ergot) and yearly total rainfall amount for the months of August and September $(r=0.72, P<0.0001)$ in the Texas Panhandle from 1997 to 2004. Rainfall data were pooled from three weather stations representing the southern (Earth), the central (Bushland), and the northern (Etter) Panhandle. 


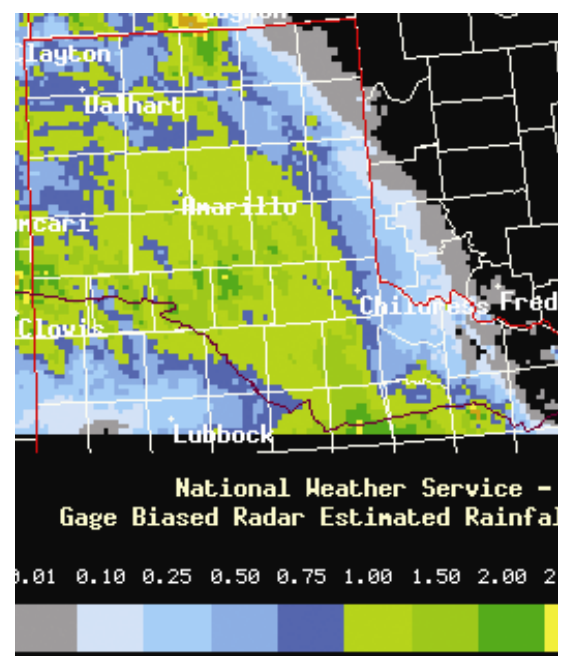

Fig. 3. NEXRAD image of a rainstorm that affected most of the Texas Panhandle during a 24-h period ending at 6:00 A.M. 29 August 2002.

Radar rainfall has been previously used to predict diseases of peanuts $(6,10)$. The radar-based peanut disease advisory program provided results comparable to the onsite gauge-based rainfall measurements. Radar-based rainfall estimates are more applicable for interpolation and regional risk assessment than gauge-based, pointmeasured rainfall estimates. Comparisons of radar-based and gauge-based rainfall estimates and factors associated with each method of measurement were described previously $(9,19)$. In this study, the two sorghum ergot severity models, based on radar estimated rainfall, were able to partition the Texas Panhandle into grids of 4 $\mathrm{km}^{2}$ exhibiting various levels of ergot severity.

The ergot pathogen can infect within $24 \mathrm{~h}$ after spore deposition and may take up to $36 \mathrm{~h}$ to reach the ovaries (2). Control of ergot was reported with some chemicals up to $36 \mathrm{~h}$ after inoculation with a spore suspension of the pathogen (16). Hence, the 18- and 24-h models may provide timely disease warnings for appropriate management actions. Even if infected florets fail to produce seeds after management action (e.g., chemical spray), suppression of honeydew development (16) is still very important because of the adverse effects of the sticky honeydew as a seed contaminant (reduction in seed quality) and its impediment of mechanical harvesting (15).

The ergot severity maps were based on HRAP $4 \mathrm{~km}^{2}$ grids, and each grid in the maps can be identified with its latitude/longitude coordinates. Because of this unique identity of each grid cell, the severity maps can potentially be developed into a web-based, site-specific ergot forecast system in which growers may use the GPS locations of their fields to assess ergot severity risk and determine whether management actions are necessary.
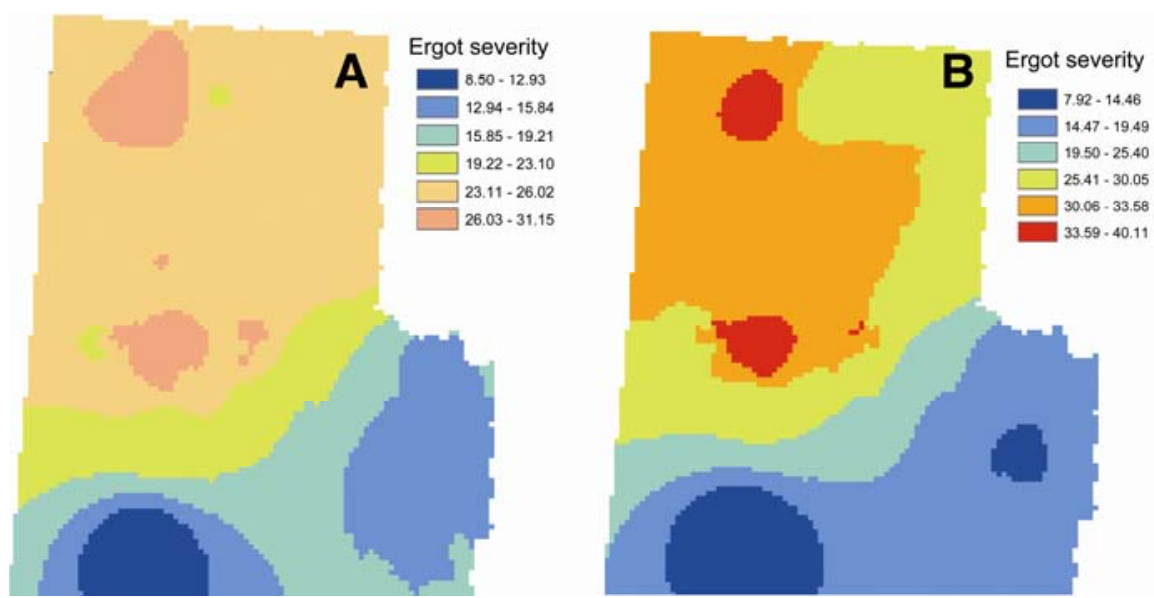

Fig. 4. Varying levels of ergot severity (\% florets affected) potential associated with the 29 August storm (Fig. 3) as predicted by the A, 18-h model and B, 24-h model.
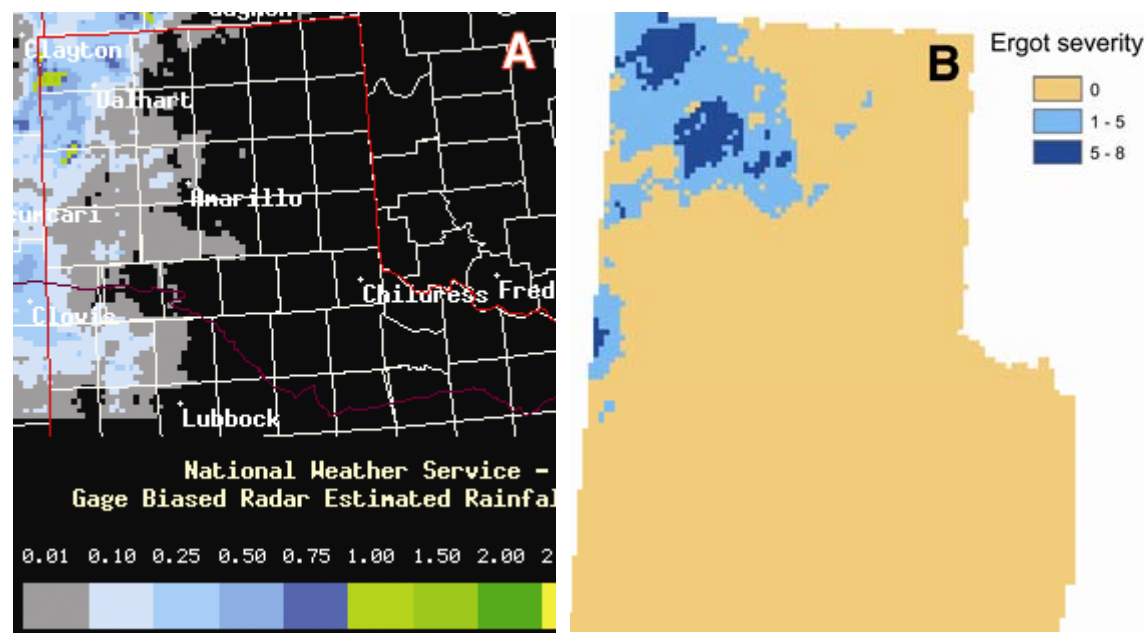

Fig. 5. A, NEXRAD image of a rain shower event in the northwestern Texas Panhandle during the 24 $\mathrm{h}$ period ending at 6:00 A.M. on 7 September 2003, and B, varying levels of sorghum ergot severity (\% florets affected) potential associated with this storm as predicted by the 24-h model.

\section{ACKNOWLEDGMENTS}

We thank Richard T. Wynne, National Weather Service in Amarillo, TX, for his useful comments and suggestions during the course of this project. We are grateful to the Arkansas-Red Basin (Tulsa, $\mathrm{OK}$ ) and the West Gulf (Ft. Worth, TX) River Forecast Centers for giving us access to NEXRAD rainfall data for the Texas Panhandle. We also thank the various seed companies in the region for their cooperation. This project was supported in part by grants from the Texas Higher Education Coordinating Board (ATP) and the Texas Agricultural Experiment Station special initiative on cropping systems.

\section{LITERATURE CITED}

1. Anonymous. 2005. United States Department of Agriculture. National Agricultural Statistics Service. US and state level data for field crops. Published online.

2. Bandyopadhyay, R., Frederickson, D. E., McLaren, N. W., Odvody, G. N., and Ryley, M. J. 1998. Ergot: A new disease threat to sorghum in the Americas and Australia. Plant Dis. 82:356-367.

3. Bosch, D. D., and Davis, F. M. 1998. Rainfall variability and spatial patterns for the southeast. Proc. 4th Int. Conf. Precision Agric., St. Paul, MN.

4. Fulton, R. A., Breidenbach, J. P., Seo, D. J., Miller, D. A., and O'Bannon, T. 1998. The WSR-88D rainfall algorithm. Weather Fore- casting 13:377-395

5. Futrell, M. C., and Webster, O. J. 1966. Host range and epidemiology of the sorghum ergot organism. Plant Dis. Rep. 50:828-831.

6. Hagan, A. K., Bowen, K. L., Bauske, E. M. Getz, R. R., and Adams, S. D. 1999. Doppler radar precipitation estimates added to AU-Pnut advisory. (Abstr.) Phytopathology 89:S32.

7. Hubbard, K. G. 1994. Spatial variability of daily weather variables in the High Plains of the USA. Agric. For. Meteorol. 68:29-41.

8. Isakeit, T., Odvody, G. N., and Shelby, R. A. 1998. First report of sorghum ergot caused by Claviceps africana in the United States. Plant Dis. 82:592.

9. Jayakrishnan, R., Srinivasan, R., and Arnold, J. G. 2004. Comparison of rain gauge and WSR-88D Stage III precipitation data over the Texas-Gulf basin. J. Hydrol. 492:135152.

10. Kemerait, R. C., Brenneman, T. B., and Hoogenboom, G. 2003. Evaluation of Dopplerradar based AU-Pnut advisory for disease management in peanut. (Abstr.) Phytopathology $93: \mathrm{S} 44$

11. Klazura, G. E., and Imy, D. 1993. A description of the initial set of analysis products available from the NEXRAD WSR-88D system. Bull. Am. Meteorol. Soc. 74:1293-1311.

12. Krajewski, W. F., Ciach, G. F., and Habib, E. 2003. An analysis of small scale rainfall variability in different climatic regions. Hydrol. 
Sci. J. 48:151-162.

13. Legates, D. R. 2000. Real-time calibration of radar precipitation estimates. Prof. Geographer 52:235-246.

14. Maunder, B. A. 2002. Sorghum worldwide. Pages 11-17 in: Sorghum and Millets Diseases. J. F. Leslie, ed. Iowa State University, Ames.

15. McLaren, N. W. 1993. Effect of sugary disease exudates on germination, seedling development and predisposition to seedling diseases of sorghum (Sorghum bicolor). S. Afr. J. Plant
Soil 10:12-16.

16. Montes, N., Odvody, G. N., and WilliamsAlanis, H. 2002. Advances in Claviceps africana chemical control. Pages 105-110 in: Sorghum and Millets Diseases. J. F. Leslie, ed. Iowa State University, Ames.

17. Reed, S. M., and Maidment, D. R. 1999. Coordinate transformations for using NEXRAD data in GIS-based hydrologic modeling. J. Hydrol. Eng. 4:174-182.

18. Sauvageot, H. 1994. Rainfall measurement by radar: A review. Atmos. Res. 35:27-54.
19. Workneh, F., Narasimhan, B., Srinivasan, R., and Rush, C. M. 2005. Potential of radarestimated rainfall for plant disease risk forecast. Phytopathology 95:25-27.

20. Workneh, F., and Rush, C. M. 2002. Evaluation of relationships between weather patterns and prevalence of sorghum ergot in the Texas Panhandle. Phytopathology 92:659-666.

21. Workneh, F., and Rush, C. M. 2006. Weather factors associated with development of sorghum ergot in the Texas Panhandle. Plant Dis. 90:717-722. 